\title{
Responsabilidade Patrimonial dos Sócios na Execução Trabalhista
}

\section{Lucas de Brandão e Mattos}

Aluno do curso de Direito da FA7.

Artigo elaborado sob orientação do Prof. Dr. João Luís

Nogueira Matias, da FA7.

lucasbmattos@hotmail.com

Sumário: 1. Considerações iniciais. 2. A responsabilização dos sócios na atual doutrina e jurisprudência trabalhistas. 3. A pessoa jurídica e o instituto da desconsideração. 4. Novas perspectivas para a fundamentação da responsabilidade dos sócios. 5. A responsabilização na execução de créditos trabalhistas. Considerações finais. Referências.

Resumo: O estudo tem por finalidade discutir a responsabilidade dos sócios de sociedade empresarial pelos créditos trabalhistas buscados pelos obreiros da empresa perante a Justiça do Trabalho. Analisa-se a posição atual da doutrina e da jurisprudência sobre o tema, com ênfase na teoria da desconsideração da pessoa jurídica, no intuito de buscar fundamentação que demonstre a real resposta do ordenamento brasileiro ao tema.

Palavras-chave: Desconsideração da Pessoa Jurídica. Responsabilidade do Sócio. Penhora de Bens dos Sócios. Execução Trabalhista.

\section{CONSI DERAÇÕES INICIAIS}

A execução é, inegavelmente, uma fase conturbada do processo, nela surgindo os mais variados óbices à satisfação do crédito declarado pelo juiz em sentença. No processo do trabalho a situação parece ainda pior, diante do problema da escassez de dispositivos legais regulamentando tal fase e da eterna dúvida sobre a aplicação subsidiária de institutos do direito processual civil.

Um desses problemas é a repentina insolvência de empresas executadas desnecessário dizer que em grande parte proveniente de fraudes. O que acontece é que, como a responsabilidade dos sócios é bastante limitada, ante a autonomia patrimonial da sociedade, o crédito do obreiro resta prejudicado. 
Os juízes trabalhistas adotam posição enérgica, utilizando-se da teoria da desconsideração da pessoa jurídica para atingir os bens dos sócios, tendo como pressuposto a mera inadimplência por parte da empresa executada.

O presente estudo se propõe a analisar essa solução da jurisprudência e doutrina trabalhistas de forma crítica. Confrontando-a, posteriormente, com o que se entende por desconsideração da pessoa jurídica no ordenamento pátrio. Por fim, propomos a construção de uma nova via para atingir a mesma finalidade, porém com fundamentação diversa, que reputamos mais harmônica com o direito nacional.

A ação dos tribunais trabalhistas, utilizando-se da teoria da desconsideração, vem recebendo críticas, principalmente dos comercialistas, visto que destoa dos princípios e requisitos em que se funda a teoria.

Deste modo, o valor do presente estudo encontra-se em tornar o processo de execução trabalhista mais célere e seguro, visto que, com premissas bem fundamentadas para responsabilizar os sócios, evitam-se recursos e protelação processual. Interessa também a proteção de instituto tão relevante quanto o da desconsideração da pessoa jurídica, que deve ser empregado dentro de seus parâmetros, pois sua deturpação leva à perda de sua utilidade, visto que aquilo que repentinamente serve para tudo acaba não servindo para mais nada.

\title{
2 ARESPONSABILIZAÇÃO DOSSÓCIOS NAATUAL DOUTRINAE JURISPRUDÊNCIATRABALHISTAS
}

A doutrina trabalhista majoritária e a jurisprudência da justiça laboral aplicam a teoria da desconsideração da pessoa jurídica para atingir os bens dos sócios uma vez que o patrimônio da sociedade se mostre insuficiente à satisfação do crédito do obreiro. Assim relata o professor Gérson Marques:

\begin{abstract}
A teoria da desconsideração da pessoa jurídica (disregard doctrine) há mais de uma década vem sendo aplicado, com relativo sucesso no Processo do Trabalho, tanto que foi abraçada em 1990 pelo Código de Defesa e Proteção do Consumidor (lei 8.78/90, art. $\left.28, \S 5^{\circ}\right)$. Neste raciocínio, não possuindo a empresa bens dignos de penhora viável, pode o constrangimento recair sobre bens dos sócios, em especial quando estes ostentarem condição de reais gestores da empresa. (LIMA, 2001, p. 455)
\end{abstract}

Para melhor ilustrar, colamos a seguinte ementa:

Execução sobre os bens do sócio - Possibilidade. A execução pode ser processada contra os sócios, uma vez que respondem com os bens particulares, mesmo que não tenham participado do processo na fase cognitiva. Na Justiça do Trabalho, basta que a empresa não possua bens para a penhora para que incida a teoria da desconsideração da personalidade jurídica da sociedade. O crédito trabalhista é 
privilegiado, tendo como base legal, de forma subsidiária, o art. 18 da Lei 8.884/94 e CTN, art. 135, caput e inciso III, c/c art. 889 da CLT (TRT $3^{\text {a }}$ R. $-2^{\text {a }}$ T. - AP n. 433/2004.098.0300-7 - Rel. João Bosco P. Lara - DJMG 9.9.04)

A base teórica dada pela doutrina funda-se no que chamam de teoria objetiva da desconsideração da personalidade jurídica, como podemos ver na lição de Mauro Schiavi:

Atualmente, a moderna doutrina e a jurisprudência trabalhista encamparam a chamada teoria objetiva da desconsideração da personalidade jurídica que disciplina a possibilidade de execução dos bens do sócio, independentemente de os atos destes terem violado ou não o contrato, ou de haver abuso de poder. Basta a pessoa jurídica não possuir bens para ter início a execução dos bens do sócio. (SCHIAVI, 2009, p. 793)

De fato, em uma análise principiológica do ordenamento jurídico brasileiro observa-se que o crédito trabalhista é diferenciado e privilegiado, em decorrência, principalmente, de seu caráter alimentar. Nada mais equânime, portanto, que dar ao trabalhador o devido por seu trabalho, que tanto gerou dividendos aos sócios. Sobre a questão é firme a posição do professor Gérson Marques:

\begin{abstract}
Portanto, o patrimônio dos sócios deve responder pelas dívidas trabalhistas da sociedade, a fim de assegurar o crédito dos empregados/exeqüentes. Não é justo que o obreiro contribua para o lucro da empresa, aumentando o patrimônio individual dos sócios e, ao final, com a "quebra", às vezes provocada, só o trabalhador e a empresa saiam prejudicados, juntamente com meia dúzia de credores. Não se pode privilegiar o patrimônio dos sócios em detrimento do crédito do trabalhador, porque isto seria inverter a ordem legal do privilégio e estimular a fraude da "industria da falência”. (LIMA, 2001, p. 457)
\end{abstract}

Portanto, temos fortes motivos para acreditar que o adimplemento do crédito do trabalhador tem precedência de acordo com o ordenamento jurídico brasileiro, conforme discorreremos adiante.

É pacífico que o fim - adimplemento do crédito trabalhista responsabilizando o sócio - é legítimo. Porém, nos parece que o meio utilizado - a desconsideração da pessoa jurídica da forma exposta - distancia-se da regulamentação dada ao instituto pela legislação, doutrina e jurisprudência.

Diante da constatação, cabe revisitar o tema de modo a fixar parâmetros para alcançar o mesmo resultado (responsabilização dos sócios), porém através de meios que possam ser considerados legítimos pelo ordenamento jurídico.

No prosseguimento do estudo fixaremos algumas premissas acerca do instituto da desconsideração da pessoa jurídica, de modo a fundamentar nosso posicionamento quanto a não ser caso de aplicação da mesma, e, em prosseguimento expor a teoria que consideramos mais adequada para buscar a responsabilização do sócio pelos débitos trabalhistas da empresa. 


\section{A PESSOAJURÍDICAE O INSTITUTO DA DESCONSIDERAÇÃO}

A pessoa jurídica é instituto proveniente do Direito Romano. Primeiramente foi reconhecida personalidade aos entes estatais, as chamas ciutates e municipia, no período clássico, para posteriormente surgirem as corporações privadas que adquiriam personalidade jurídica caso obedecessem certos requisitos, sobre os quais ensina Moreira Alves:

Os requisitos para constituição da corporação eram os seguintes:

a) que, no momento de sua constituição, houvesse, pelo menos, três pessoas para se associarem;

b) estatuto - denominado, nas fonte, L ex collegi ou L ex municipii - onde se regulasse sua organização e funcionamento; e

c) que sua finalidade - assim, por exemplo, religiosa, política, comercial - fosse lícita. (ALVES, 1997, p. 135)

Da Roma antiga aos dias atuais as corporações se tornaram bastante sofisticadas e formam, atualmente, a base da economia capitalista, pautada na livre iniciativa, que vigora na maioria dos países do globo.

Sem dúvida, a utilização da pessoa jurídica decorre principalmente dos princípios da autonomia e da separação patrimonial, que tornam interessante ao empreendedor juntar-se a outros interessados e constituir uma sociedade. No Brasil, a sua importância cresceu nas primeiras décadas do século XX, quando a evolução dos tipos societários trouxe menor responsabilização dos sócios, incentivando o início da industrialização nacional.

No final do século XIX surgiram os primeiros sinais de possibilidade de quebra do princípio da autonomia, que originaria mais tarde a disregard of legal entity doctrine, também denominada de lifting the corporate veil, em referência ao "véu" que separaria o patrimônio da sociedade do patrimônio do sócio. O leading case, que viria a originar a teoria, é o chamado Solomon vs. Solomon \& C 0., ocorrido nos Estados Unidos em 1895, no qual o juiz desconsiderou a autonomia patrimonial da sociedade. A decisão foi confirmada pelo tribunal, mas, na última instância, foi revogada, evidenciando que ainda era frágil e revolucionária a ideia.

Somente na década de 1950 foi desenvolvido estudo profundo e sistematizado, de autoria de Rolf Serick, que serve de base à doutrina até os dias atuais. No Brasil, a teoria foi disseminada por Rubens Requião, em meados da década de 60, seguindo-se aplicação jurisprudencial incipiente, com fundamento único na mencionada doutrina.

A regulamentação legal tardou e veio primeiro apenas para campos especializados. A primeira norma regulamentadora foi o art. 28, §5º do Código de Defesa do Consumidor - Lei 8078/90. Posteriormente vieram a Lei 8884/94, aplicável às infrações à ordem econômica, e a Lei 9605/98, lei de crimes ambientais. Todas essas 
leis traziam dispositivos que adotavam a disregard doctrine em seu respectivo âmbito. Porém, só com a promulgação do Código Civil de 2002 tivemos regulamentação do instituto para aplicação geral. Sobre o tema, ensina André Ramos:

$\mathrm{O}$ art. 50 do GG é, atualmente, a regra matriz acerca da disregard doctrine no direito brasileiro, sendo de aplicação obrigatória, portanto, a todos os casos de desconsideração da personalidade jurídica, com exceção dos referentes às relações de consumo, aos crimes ambientais e às infrações à ordem econômica, os quais, como visto, possuem disciplina própria prevista em leis especiais (RAMOS, 2009, p. 332).

Com base na legislação atual, no Brasil, a doutrina e a jurisprudência reconhecem que há duas teorias da desconsideração da pessoa jurídica, uma chamada teoria maior, a do Código Civil, aplicável como regra geral, e outra chamada teoria menor, adotada pelo Código de Defesa do Consumidor, aplicável às relações de consumo. Sobre o tema é esclarecedora a jurisprudência do STJ:

RESPONSABILIDADE GIVIL E DIREITO DO CONSUMIDOR. RECURSO ESPECIAL. SHOPPING CENTER DE OSASCO-SP. EXPLOSÃO. CONSUMIDORES. DANOS MATERIAIS E MORAIS. MINISTÉRIO PÚBLICO. LEGITIMIDADE ATIVA. PESSOA JURÍDICA. DESCONSIDERAÇÃO. TEORIA MAIOR E TEORIA MENOR. LIMITE DE RESPONSABILIZAÇÃO DOS SÓCIOS. CÓDIGO DE DEFESA DO CONSUMIDOR. REQUISITOS. Obstáculo ao ressarcimento de prejuízos causados aos consumidores. Art. 28, § 5 . - Considerada a proteção do consumidor um dos pilares da ordem econômica, e incumbindo ao Ministério Público a defesa da ordem jurídica, do regime democrático e dos interesses sociais e individuais indisponíveis, possui o Órgão Ministerial legitimidade para atuar em defesa de interesses individuais homogêneos de consumidores, decorrentes de origem comum. - A teoria maior da desconsideração, regra geral no sistema jurídico brasileiro, não pode ser aplicada com a mera demonstração de estar a pessoa jurídica insolvente para o cumprimento de suas obrigações. Exige-se, aqui, para além da prova de insolvência, ou a demonstração de desvio de finalidade (teoria subjetiva da desconsideração), ou a demonstração de confusão patrimonial (teoria objetiva da desconsideração). - A teoria menor da desconsideração, acolhida em nosso ordenamento jurídico excepcionalmente no Direito do Consumidor e no Direito Ambiental, incide com a mera prova de insolvência da pessoa jurídica para o pagamento de suas obrigações, independentemente da existência de desvio de finalidade ou de confusão patrimonial. - Para a teoria menor, o risco empresarial normal às atividades econômicas não pode ser suportado pelo terceiro que contratou com a pessoa jurídica, mas pelos sócios e/ou administradores desta, ainda que estes demonstrem conduta administrativa proba, isto é, mesmo que não exista qualquer prova capaz de identificar conduta culposa ou dolosa por parte dos sócios e/ou administradores da pessoa jurídica.- A aplicação da teoria menor da desconsideração às relações de consumo está calcada na exegese autônoma do $\S 5^{\circ}$ do art. 28, do CDG, porquanto a incidência desse dispositivo não se subordina à demonstração dos requisitos previstos no caput do artigo indicado, mas apenas à prova de causar, a mera existência da pessoa jurídica, obstáculo ao ressarcimento de prejuízos causados aos consumidores. - Recursos 
especiais não conhecidos.(REsp 279273/SP, Rel. Ministro ARI PARGENDLER, Rel. p/ Acórdão Ministra NANCY ANDRIGHI, TERCEIRA TURMA, julgado em 04/12/2003, DJ 29/03/2004 p. 230)

Há ainda quem fale em teoria subjetiva ou objetiva, porém trata-se apenas de concepções quanto aos requisitos para aplicação da teoria maior. A doutrina tradicional exigia a prova da intenção de fraude, subjetiva portanto, porém a concepção adotada atualmente, de cunho objetivo, propugna pela caracterização de dados empíricos como o desvio de finalidade ou a confusão patrimonial. A segunda doutrina é fruto, principalmente, dos estudos do professor Fábio Konder Comparato e é a teoria adotada pelo art. 50 do CC:

Art. 50. Em caso de abuso da personalidade jurídica, caracterizado pelo desvio de finalidade, ou pela confusão patrimonial, pode o juiz decidir, a requerimento da parte, ou do Ministério Público quando lhe couber intervir no processo, que os efeitos de certas e determinadas relações de obrigações sejam estendidos aos bens particulares dos administradores ou sócios da pessoa jurídica.

O instituto da desconsideração da pessoa jurídica é um poder dado ao juiz para, no caso concreto, tornar sem efeito a personalização e a autonomia da sociedade, que são instituídas pela própria lei. Como todo poder dado ao juiz a lei prescreve situação hipotética dependendo do juízo de subsunção do fato concreto aos requisitos da norma legal para a aplicação. Enfim, o juiz só está autorizado a desconsiderar a pessoa jurídica quando demonstrada a presença dos requisitos adotados pela legislação.

O exposto no parágrafo anterior pode parecer elementar, porém extremamente necessário para a conclusão de que as decisões dos juízes trabalhistas, que dizem aplicar a desconsideração da pessoa jurídica, devem respeito ao art. 50 do $\mathrm{CC}$, não sendo aplicável diante da mera insolvência da sociedade.

Porém, a desconsideração da pessoa jurídica não é a única via para atingir o patrimônio dos sócios, visto que a legislação pátria admite a responsabilização direta do sócio em vários casos, como de obrigações tributárias, previsto no art. 135 do CTN, excesso de mandato ou violação do estatuto, arts. 1015 e art. 1016, ambos do CC/02. Sobre o tema, ensina a professora Thereza Nahas:

\footnotetext{
Somente é cabível falar em desconsideração da personalidade jurídica quando a responsabilidade pelo ato não puder ser imputada diretamente ao sócio, administrador ou qualquer outra pessoa jurídica. Ou seja, somente terá pertinência falarmos em desconsiderar a pessoa jurídica quando a personalidade que a lei lhe atribui é obstáculo à consecução dos fins a que se destina, ou essa personalização desviar-se dos fins sociais para o qual foi suportada e aceita pelo direito. Caso contrário, não há razão para se aplicar o instituto da desconsideração, pelo simples fato de que a própria lei permite a responsabilização direta do sócio ou administrador, sem qualquer necessidade de se comprovar desvio, fraude ou qualquer das situações previstas nas disposições legais [....] (NAHAS, 2004, p.153).
} 
Acreditamos que a responsabilidade patrimonial do sócio na execução trabalhista é um dos casos de responsabilização direta do sócio, o capítulo seguinte é dedicado a demonstrar os fundamentos que nos levam a sustentar esta posição.

\section{NOVAS PERSPECTIVAS PARAA FUNDAMENTAÇÃO DARESPONSABI LIDADE DOS SÓCIOS}

Como exposto no capítulo anterior, a responsabilização direta, por previsão legal, é um modo de atingir o patrimônio dos sócios sem utilizar-se da teoria da desconsideração.

Em matéria tributária, no art. 135 do CTN, há previsão expressa da responsabilidade dos sócios pelos débitos tributários. O dispositivo tem a seguinte redação:

\footnotetext{
Art. 135. São pessoalmente responsáveis pelos créditos correspondentes a obrigações tributárias resultantes de atos praticados com excesso de poderes ou infração de lei, contrato social ou estatutos:

I - as pessoas referidas no artigo anterior;

II - os mandatários, prepostos e empregados;

III - os diretores, gerentes ou representantes de pessoas jurídicas de direito privado.
}

O dispositivo inclui ainda os sócios comuns, de acordo com o art. 134, VII. A jurisprudência e doutrina são pacíficas quanto à força do artigo em responsabilizar sócios, gerentes e quaisquer outros que estejam envolvidos com o débito por violação à lei. A CLT traz previsão de aplicação de normas de processo tributário no art. 889, que assim dispõe:

Art. 889 - Aos trâmites e incidentes do processo da execução são aplicáveis, naquilo em que não contravierem ao presente Título, os preceitos que regem o processo dos executivos fiscais para a cobrança judicial da dívida ativa da Fazenda Pública Federal.

Da leitura do artigo a melhor interpretação é de que todas aquelas normas reguladoras do processo tributário, utilizadas na cobrança dos créditos da Fazenda Pública, têm aplicação subsidiária ao Processo do Trabalho. Conclui-se, então, que o art. 135 do CTN só poderá responsabilizar o sócio por débitos, na justiça laboral, caso tenha natureza processual. Sobre o tema cabe lição de Wagner Giglio:

\footnotetext{
Restringe-se, porém, a aplicação subsidiária, nos termos do art. 889 da CLT, aos "preceitos que regem o processo dos executivos fiscais para a cobrança judicial..." (grifamos). Assim sendo, as normas de direito material, contidas em bom número na Lei n. 6.830/80, não se aplicam ao processo de execução trabalhista, em que incidem apenas as normas de natureza processual. (GIGLIO; GORRÊA, 2005, p. 526)
}

Em uma análise superficial, pode parecer ser de natureza material a norma em comento, tendo em vista que se encontra no CTN. Porém, o dispositivo tem natureza processual, segundo os argumentos que agora vamos dispor. 
A temática do dispositivo em comento é a responsabilidade patrimonial secundária, regulada hipoteticamente pelo art. 592, I, e pelo art. 596 do CPC. Trata-se, portanto, de relação jurídica que surge no curso da execução, sujeitando os bens do sócio à pretensão do exequente. Elucidativa é a lição do Ministro Teori Zavacski:

Na estrutura de uma norma jurídica individualizada de natureza creditícia pode-se
identificar: (a) no enunciado da endonorma, um sujeito (devedor) obrigado a entregar
a outro (credor) uma determinada prestação; e (b) no enunciando da perinorma, o
Estado-juiz com o poder-dever de fazer atuar coativamente sobre determinados bens
a sanção prevista para o não atendimento do preceito endonormativo. Da relação
que existe entre os figurantes da endonorma (credor e devedor) nasce o débito, ou
seja, o dever de prestar; e, da relação que se estabelece entre o Estado e o sujeito
sobre cujo patrimônio recai a sanção jurídica, nasce a responsabilidade, ou seja, a
sujeição dos bens ao atendimento coativo da prestação. O débito está relacionado
com o preceito que define a conduta do devedor ao seu atendimento espontâneo; a
responsabilidade, diferentemente, só ganha sentido e função com inadimplemento
do preceito e com a execução forçada da prestação.
Acertada, portanto, ao contrário do que afirma certa corrente doutrinária, a
preocupação do legislador em disciplinar, em capítulo do Código de Processo, o
tema da responsabilidade patrimonial. Trata-se, com efeito, de instituto de natureza
processual, cuja invocação e atuação é desencadeada em decorrência da crise que
se estabelece pelo não cumprimento espontâneo da obrigação e pela conseqüente
necessidade do recurso à tutela coativa do Estado. (ZAVACSKI, 2000, p. 260)

O posicionamento exposto é corroborado pela doutrina italiana clássica de Carnelluti e Liebman, como também pela autorizada doutrina nacional de Humberto Theodoro Júnior e Cândido Rangel Dinamarco.

Ante os preceitos fincados, reputamos clara a responsabilidade do sócio, com fundamento no art. 135, do CTN c/c art. 889, da CLT, sob a premissa de que o dispositivo tributário possui natureza processual.

Quanto à responsabilidade do sócio-gerente e do administrador, a legislação traz outros dispositivos que apontam para a mesma direção. A responsabilização do sócio-administrador estava presente na lei que regulava a constituição das sociedades limitadas - tipo societário da imensa maioria das empresas brasileiras - o Decreto 3.708/19. O art. 10 da norma em tela dispõe:

Art. 10 - Os sócios-gerentes ou que derem o nome à firma não respondem pessoalmente pelas obrigações contraídas em nome da sociedade, mas respondem para com esta e para com terceiros solidária e ilimitadamente pelo excesso de mandato e pelos atos praticados com violação do contrato ou da lei.

Porém, o Novo Código Civil regula a responsabilidade do administrador, revogando tacitamente o mencionado Decreto 3.708/19. Assim dispõe o Codice: 
Art. 1.015. No silêncio do contrato, os administradores podem praticar todos os atos pertinentes à gestão da sociedade; não constituindo objeto social, a oneração ou a venda de bens imóveis depende do que a maioria dos sócios decidir.

Parágrafo único. O excesso por parte dos administradores somente pode ser oposto a terceiros se ocorrer pelo menos uma das seguintes hipóteses:

I - se a limitação de poderes estiver inscrita ou averbada no registro próprio da sociedade;

II - provando-se que era conhecida do terceiro;

III - tratando-se de operação evidentemente estranha aos negócios da sociedade.

Art. 1.016. Os administradores respondem solidariamente perante a sociedade e os terceiros prejudicados por culpa no desempenho de suas funções.

Da leitura do art. 1.015, podemos depreender que a responsabilidade por violação do contrato e por excesso de mandato continuam previstas; haveria omissão apenas quanto à responsabilidade por violação da lei para coincidir com a amplitude da norma do Decreto 3.708/19. Porém, o art. 1016 vai além, responsabilizando o administrador quando agir com culpa.

Diante desses dispositivos, percebemos que a norma buscou ampliar a responsabilidade do administrador em relação à disciplinada anteriormente no Decreto 3.708/19. A responsabilidade por violação à lei é a de menor amplitude e mais elementar, visto que decorre da própria lógica do Estado Constitucional. Portanto, se a norma prevê a responsabilização dos sócios por violações de menor vulto, como a do contrato social e qualquer outra que decorra de culpa do administrador, em uma interpretação sistemática e teleológica, reputamos haver responsabilidade também pelos atos de violação à lei.

Interpretação diversa, fincada em interpretação literal da norma, desrespeitaria o terceiro, que sofreu o dano em decorrência da violação à lei, o qual muitas vezes está em situação de hipossuficiência, como é o caso do consumidor e do empregado. A referida interpretação esbarraria no chamado princípio da vedação ao retrocesso, formulado pelo professor Canotilho, que identifica na Constituição efeito que proíbe que as conquistas históricas em matéria de direitos sociais sejam tolhidas (art. $3^{\circ}$, art. $7^{\circ}$, art. $5^{\circ}, \S 2^{\circ}$, da $\mathrm{CF} / 88$ ) - efeito cliquet. A estrada dos direitos fundamentais só leva à frente; nunca deve haver retrocesso.

Portanto, havendo excesso de mandato, violação do contrato social, violação da lei ou culpa no exercício das funções, os administradores respondem solidariamente pelas dívidas da sociedade perante terceiros.

O crédito trabalhista tem contornos próprios, de forte proteção caracterizada em nossa legislação. Com esse preceito em mente, pretendemos provar, a seguir, que o inadimplemento do crédito trabalhista constitui violação da lei, ocasionando a responsabilidade subsidiária dos sócios com base nos dispositivos legais já mencionados.

O valor social do trabalho é um dos pilares de nosso sistema econômico, ao lado da livre iniciativa, ambos insculpidos como fundamentos da República Federativa 
do Brasil no primeiro artigo de nossa Carta Política. Portanto, a desvalorização do trabalho, decorrente do não pagamento de salários e verbas conferidas pela lei ao obreiro, leva à ruína o sistema almejado pela Constituição. A força de trabalho dispensada pelo empregado ao patrão não se restaura, de modo que, não havendo contraprestação, restará o enriquecimento ilícito, beneficiando-se o patrão de sua própria torpeza.

A função social da empresa é princípio decorrente da função social da propriedade, presente no art. $5^{\circ}$, XXIII, da CF/88 e, embora presente apenas na legislação infraconstitucional, tem eficácia de direito fundamental por integrar o bloco de constitucionalidade (cf. art. $5^{\circ}, \S 2^{\circ}$, da Carta Magna). Desse mandamento decorre uma série de responsabilidades sociais que os detentores do empreendimento devem ter em mente, com vistas a cumprir seu papel dentro da sociedade, não sendo admissível que a empresa sirva para o enriquecimento de alguns em detrimento de outros. Sem dúvida, muito da responsabilidade é assumida em favor dos trabalhadores da empresa, que despendem a maior parte de sua vida construindo o empreendimento e o patrimônio pessoal dos sócios.

O princípio da proteção, insculpido no art. $7^{\circ}$ da Constituição Federal, é o princípio basilar do Direito do Trabalho, que, reconhecendo a hipossuficiência do trabalhador em relação ao empregador, põe o Direito ao lado do primeiro, equacionando a fórmula. Conclui-se, então, que a interpretação e aplicação do Direito deve sempre ter em vista a questão social e posicionar-se ao lado do mais fraco: o trabalhador.

O princípio da alteridade faz-se presente na Consolidação das Leis do Trabalho ao definir o empregador em seu art. $2^{\circ}$ :

Art. $2^{\circ}$ - Considera-se empregador a empresa, individual ou coletiva, que, assumindo os riscos da atividade econômica, admite, assalaria e dirige a prestação pessoal de serviço.

Portanto, como somente o empregador assume o risco da atividade econômica, somente ele terá as dívidas e revezes do empreendimento, mas também ficará sozinho com os lucros. Nessa esteira, o salário do empregado deverá ser sempre pago, não podendo haver qualquer vinculação entre o recebimento de salários e o sucesso do empreendimento de modo a prejudicar o empregado. $\mathrm{O}$ mesmo artigo, em seu segundo parágrafo, explicita uma tendência de ir além da sociedade empregadora, atingindo os grupos empresariais informais. Tal dispositivo legal levou Maria Helena Diniz a classificá-lo como primeiro dispositivo de influência da desconsideração da pessoa jurídica em nossa legislação. Assim dispõe a civilista:

No Brasil não havia que se falar em "desconsideração" no âmbito legal. Esse princípio só existia, entre nós, em alguns casos jurisprudenciais esparsos. Todavia, a Consolidação das Leis do Trabalho, no seu art. $2^{\circ}, \xi 2^{\circ}$, parece aplicar a teoria da desconsideração ao prescrever que "sempre que uma ou mais empresas, tendo, 
embora, cada uma delas, personalidade jurídica própria, estiverem sob a direção, controle ou administração de outra, constituindo grupo industrial, comercial ou de qualquer outra atividade econômica, serão, para os efeitos da relação de emprego, solidariamente responsáveis a empresa principal e cada uma das subordinadas. (DINIZ, 2005, p. 289)

Portanto, vemos que o princípio da alteridade impera sobre o formalismo do vínculo com a pessoa jurídica, sendo também responsável pela contraprestação do trabalho aquele que, presumidamente, aufere os lucros provenientes do mesmo.

O princípio da primazia da realidade, presente no art. $9^{\circ}$ da CLT, propugna a superioridade absoluta da materialidade dos fatos independente da forma adotada, de modo a tornar nulos quaisquer atos que - mesmo com forma juridicamente legítima - tenham por escopo a fraude às leis trabalhistas. Com clarividência podese observar que, a partir desse princípio, a autonomia patrimonial da pessoa jurídica jamais poderá ser obstáculo à persecução dos fins da legislação trabalhista, ou seja, o adimplemento do crédito do empregado.

Ante o exposto, parece claro que o inadimplemento do crédito trabalhista constitui violação à lei, por desrespeito aos dispositivos constitucionais do art. $1^{\circ}$, IV, art. $5^{\circ}$, XIII, art. $5^{\circ}, 2^{\circ}$ e art. $7^{\circ}$, caput, como também aos mandamentos dos arts. $2^{\circ} \mathrm{e}$ $9^{\circ}$ da CLT. Portanto, presente a violação à lei, o magistrado está autorizado a buscar a responsabilização patrimonial do sócio, com fulcro no art. 135 do CTN c/c o art. 889 da CLT, ou somente do sócio-gerente ou do administrador, com base nos arts. 1.015 e 1.016 do $\mathrm{CG} / 02$.

\section{ARESPONSABILIZAÇÃO NAEXECUÇÃO DE CRÉDITOSTRABALHISTAS}

No sentido de guiar melhor a atuação prática da responsabilização dos sócios na execução de créditos trabalhistas, julgamos apropriado discorrer sobre algumas questões, em sua maioria de ordem procedimental, que geram dúvidas na doutrina e jurisprudência.

Primeiramente, cumpre esclarecer que consideramos desnecessário, para fins de responsabilização do sócio, que o mesmo tenha participado como reclamado no processo de conhecimento, pois sua responsabilidade é subsidiária e decorrente da lei, como já exposto, o devedor é a pessoa jurídica, presente no título executivo judicial, e somente diante da insolvência na execução se recorrerá aos bens dos sócios (art. 592, II e art. 596, ambos do CPC).

Deve o sócio então, na fase de execução, depois de constatada a insolvência da empresa, ser citado para pagar no prazo de 15 dias na forma do art. 475-J do CPC, de aplicação subsidiária ao processo trabalhista. 
Uma questão que gera muita controvérsia é o meio processual idôneo para defesa do sócio depois de citado na fase de execução. No caso, caberiam embargos do executado ou embargos de terceiro? Sobre o tema trazemos à colação julgado que parece dirimir a questão:

\begin{abstract}
EMBARGOS DE TERCEIRO - SÓCIO - LEGITIMIDADE 'AD CAUSAM' PRINCÍPIO DA FUNGIBILIDADE - A responsabilização patrimonial do sócio não implica na sua inclusão automática no pólo passivo da execução de sentença, já que essa legitimidade pressupõe sua participação no processo de conhecimento. Se a parte, mesmo sendo sócia da reclamada, não participou da fase cognitiva, é lógico que ela não configura no título executivo como devedora, daí porque não é absoluto, do ponto de vista jurídico, afirmar que a defesa da posse ou da propriedade de bens deva ser efetivada através de embargos à execução, sobretudo porque há equivalência dos dois institutos jurídicos, embargos à execução e embargos de terceiro, pois a parte que teve seus bens constritados pode pleitear a insubsistência da penhora em um como no outro. Esse fato, robustecido pela controvérsia que paira a nível jurisprudencial acerca da medida cabível, legitima o sócio da executada para a ação de embargos de terceiro. Quando nunca, caberia ao d. Julgador monocrático receber uma ação pela outra, pelo princípio da fungibilidade das medidas judiciais, mormente quando não se vislumbra a existência de erro grosseiro na hipótese vertente. Agravo de petição provido. (TRT/3 ${ }^{a}$ região, AP 4429/1999, rel. Juiz Gilberto Goulart Pessoa, DJMG, 19 abr. 2000, p.7)
\end{abstract}

Portanto, depreende-se do julgado que, como o sócio não é realmente parte no processo, visto que não consta no título executivo, seria mais correto, formalmente, optar pelo embargo de terceiro. Porém com atenção à instrumentalidade das formas, visto não haver prejuízo, caso propostos embargos à execução, devem ser recebidos, em atenção ao princípio da fungibilidade.

Por último, cabe tratar da responsabilidade do sócio retirante. O sócio que já não mais faz parte do empreendimento pode ser chamado a responder pelos créditos trabalhistas inadimplidos pela empresa? A questão é delicada e vai depender muito da situação da empresa no momento da saída do sócio. Se, no momento da retirada do sócio, a sociedade estava funcionando em completa regularidade, adimplidos todos os salários e demais parcelas, não deve ser atribuída responsabilidade ao mesmo, visto que o crédito é consequência de momento posterior à sua saída quando não mais respondia pelos riscos do empreendimento. Portanto, caberá a responsabilização do sócio retirante quando no momento da sua saída haja dívidas da empresa para com seus obreiros ou haja ocorrido fraude na cessão ou transferência das quotas societárias. Porém, não responderá eternamente pelos débitos da empresa que deixou, mas apenas pelo período de dois anos, como dispõe o Código Civil:

Art. 1.032. A retirada do sócio, não o exime, ou a seus herdeiros, da responsabilidade pelas obrigações sociais anteriores, até dois anos após averbada a resolução da sociedade; nem nos dois primeiros casos, pelas posteriores e em igual prazo, enquanto não se requerer averbação. 
Portanto, em termos simples o sócio retirante responderá pelas execuções desde que a ação de conhecimento tenha sido ajuizada até dois anos após a averbação de sua retirada da sociedade no contrato social.

\section{CONSIDERAÇÕES FINAIS}

O ideal seria que Processo do Trabalho dispusesse de norma expressa, no texto da CLT ou de suas leis esparsas, nos moldes do art. 28 do CDC, prevendo desconsideração da pessoa jurídica ante a mera inadimplência. Pois, os motivos que levaram à adoção do preceito para a defesa do consumidor também estão presentes na seara trabalhista, ligados principalmente à hipossuficiência na relação jurídica que ambos detêm com a empresa.

Não obstante a mora legislativa, com fulcro nas afirmações do presente estudo reputamos como esclarecido que a responsabilização do sócio - por via teoria da desconsideração da pessoa jurídica - tem se dado de modo equivocado pelos magistrados trabalhistas, ante a distância dos requisitos legais.

Porém, não se faz necessária a distorção da disregard doctrine, visto que há fundamento para responsabilização direta do sócio por expressa previsão legal, por violação à lei, na forma dos dispositivos já citados exaustivamente. A violação à lei está fundada nos dispositivos comentados da Constituição Federal e da CLT.

Deste modo, reputamos que a presente teoria da responsabilidade subsidiária dos sócios pelos créditos trabalhistas encontra-se estruturada em pilares sólidos na legislação pátria e pronta para ser aplicada aos feitos em curso, tornando mais efetiva e célere a fase de execução e, por via colateral, o Direito do Trabalho.

\section{REFERÊNCIAS}

MOREIRA ALVES, José Carlos. Direito Romano. v. 1. 10. ed. Rio de Janeiro: Forense, 1997.

DINIZ, Maria Helena. Curso de Direito Civil Brasileiro: teoria geral do direito civil. v. 1. 22. ed. São Paulo: Saraiva, 2005.

GIGLIO, Wagner D.; CORRÊA, Cláudia Giglio Veltri. Direito Processual do Trabalho. 15. ed. São Paulo: Saraiva, 2005.

LIMA, Gérson Marques de. Direito Processual do Trabalho. 3. ed. São Paulo: Malheiros, 2001.

NAHAS, Thereza Christina. Desconsideração da Pessoa Jurídica: reflexos civis e empresariais do direito do trabalho. São Paulo: Atlas, 2004. 
RAMOS, André Luiz Santa Cruz. Curso de Direito Empresarial. 3. ed. Salvador: JusPodivm, 2009.

SCHIAVI, Mauro. Manual de Direito Processual do Trabalho. 2. ed. São Paulo: LTr, 2009.

ZAVACSKI, Teori Albino. Comentários ao Código de Processo Civil: do Processo de execução arts. 566 a 645. v. 8. São Paulo: Revista dos Tribunais.

\title{
PARTNER'SRESPONSIBILITY BEFORE LABOR JUDICIAL DECISIONS
}

\begin{abstract}
This study focuses on the partner's responsibility for the credits earned by the company employees in enforcement of labor judicial decisions. Through the analysis of the current jurisprudence and doctrine about the theme, it envisages the disregard of the legal entity doctrine in order to seek fundaments that show the real aspects of the Brazilian law on the current matter.
\end{abstract}

Keywords: Labor Sentence Enforcement. Disregard of Legal Entity Doctrine. Partner's Responsibility. 